\title{
Aneurysmal bone cyst of proximal fibula treated with en-bloc excision: a rare case report
}

\author{
Piyush Wadhawan*, Atul Agrawal, Ruchit Khera
}

\begin{abstract}
Department of Orthopedics, Himalayan Institute of Medical Sciences, Swami Rama Himalayan University, Dehradun, India
\end{abstract}

Received: 21 February 2019

Revised: 06 April 2019

Accepted: 09 April 2019

\author{
*Correspondence: \\ Dr. Piyush Wadhawan, \\ E-mail: piyush.wadhawan@gmail.com
}

Copyright: () the author(s), publisher and licensee Medip Academy. This is an open-access article distributed under the terms of the Creative Commons Attribution Non-Commercial License, which permits unrestricted non-commercial use, distribution, and reproduction in any medium, provided the original work is properly cited.

\begin{abstract}
Aneurysmal bone cysts (ABCs) are benign but locally destructive, blood filled reactive lesions of the bone. Although a wider age group may be affected, most commonly they are seen in patients younger than 20 years of age, with a slight female preponderance. Most common sites include metaphysis of femur followed by tibia and then humerus. Vertebral lesions involving the posterior elements are common.Aneurysmal bone cyst of proximal fibula is a rare and uncommon. Here, we report a case of 13 year old female with classic histologic, clinical, and radiographic findings that was treated by en bloc resection.
\end{abstract}

Keywords: Aneurysmal bone cysts, Fibula, Rare case

\section{INTRODUCTION}

Aneurysmal bone cyst (ABC) is classically explained as a non malignant lesion budding mostly in the metaphyses of long bones and in vertebral bodies. ${ }^{1}$ Typical histological picture shows blood filled spaces separated by connective tissue septa containing osteoclast-like giant cells, fibroblasts and reactive woven bone. ${ }^{2}$ The distal femur, proximal tibia, proximal humerus followed by spine with its preference being metaphysis of long bones are most common sites of its occurence . Aneurysmal bone cyst itself accounts for less than $6 \%$ of all bone tumours and is 4 times more rarer than osteosarcoma. ${ }^{3}$ The etiology of Aneurysmal bone cyst still remains uncertain however many anticipated that it may result from local circulatory interruption which leads to increased venous pressure and local hemorrhage production. Lesions usually appear on x-rays films as expansile and lytic. magnetic resonance imaging and Computed tomography often show a heterogeneous lesion with fluid-filled cystic spaces encircled by a thin rim of bone. ${ }^{4}$ Standard management of ABCs with marginal, yet complete surgical excision has shown satisfactory results.

\section{CASE REPORT}

A 13 year old female child presented to our opd with pain and gradual swelling in proximal third right leg since 1 years. There is no history of trauma, fever. There were no associated symptoms. On clinical examination, a swelling was present in the anterolateral aspect of proximal right leg. Swelling was tender on deep palpation, bony hard in consistency , ovoid in shape, irregular margin, non mobile. There was very mild local rise of temperature and without any other signs of inflammation like erythema, induration. Movements of the knee joint were non restricted and she had normal bipedal gait. Routine Blood investigations and Chest Xray were in normal limits. Plain radiograph of the knee joint with leg in anterio-posterior and lateral view revealed an expansile lytic lesion that elevates the periosteum at proximal end of fibula, limited by a thin shell of cortical bone (Figure-1). MRI of right knee joint with leg showed that there is a heterogenous enhancing 


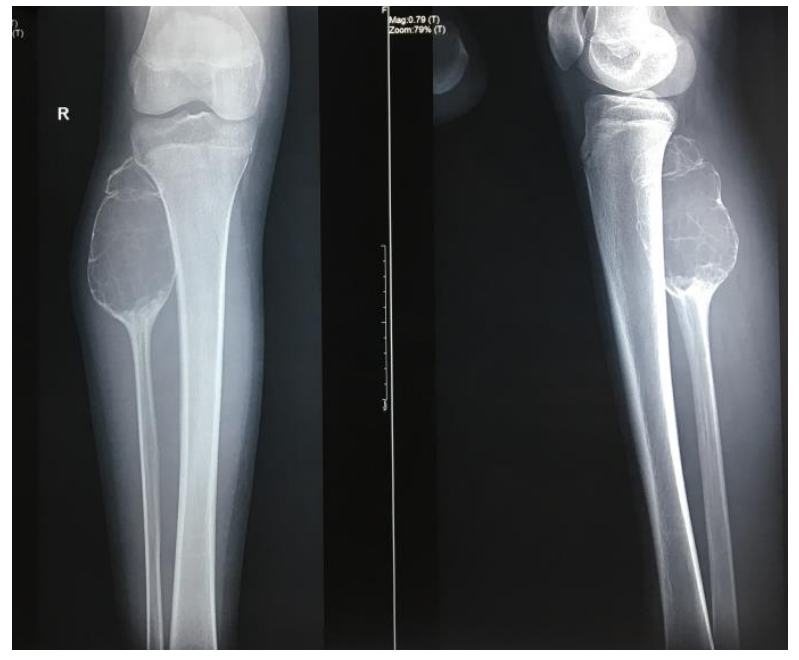

Figure 1: Plain radiograph of the knee joint with leg in anterio-posterior and lateral view revealed an expansile lytic lesion.

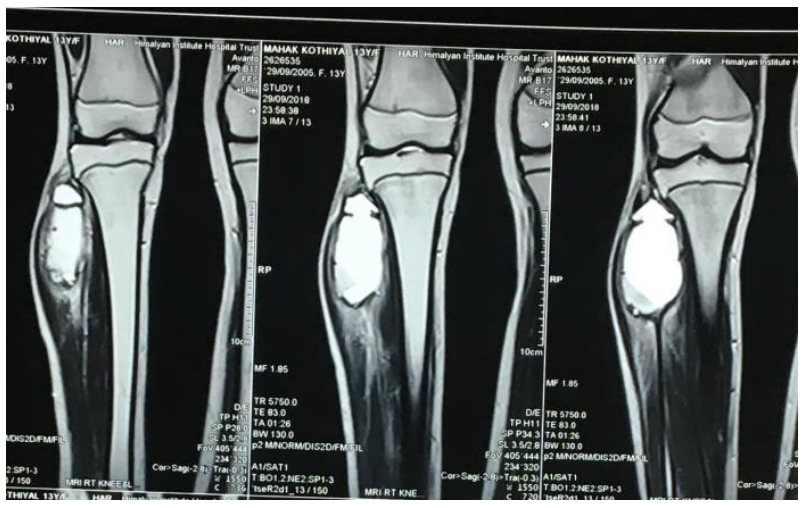

Figure 2: MRI of right knee joint with leg showed that there is a heterogenous enhancing expansile lesion of size $8.8 \times 5.1 \times 4.8 \mathrm{~cm}$ in proximal

epimetaphysial region of fibula with blood fluid levels.

expansile lesion of size $8.8 \times 5.1 \times 4.8 \mathrm{~cm}$ in proximal epimetaphysial region of fibula with blood fluid levels (Figure-2). Patient was then explained in detail about the treatment. We planned and then posted for surgery. Under torniquet control, proximal end of fibula was excised sufficiently and sample send for histo pathological examination (Figure-3). Biopsy report showed multiple cavernous cystic cavities of variable size filled with blood and separated by thick fibro collagenous septae suggestive of Aneurysmal Bone Cyst of Proximal Fibula. Post operative (Anteroposterior and Lateral) radiographs showing en-bloc excision of $\mathrm{ABC}$ from proximal end of fibula (Figure-4).

\section{DISCUSSION}

In 1942 Jaffe and Lichenstein described aneurysmal bone cyst is a bony tumor which is osteolytic described by generally non-endothelialized spaces of various diameters, several sponge-like blood or serum filled. ${ }^{5}$

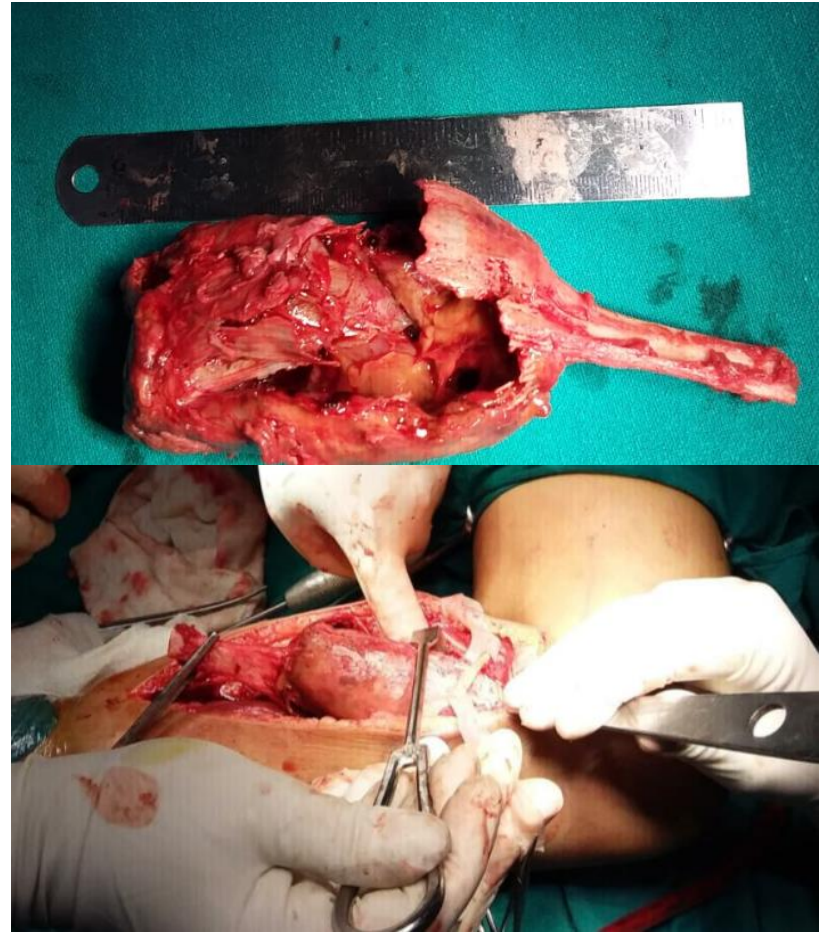

Figure 3: Intra-operative and Gross specimen photos showing the excised mass with attached membranous soft tissue.

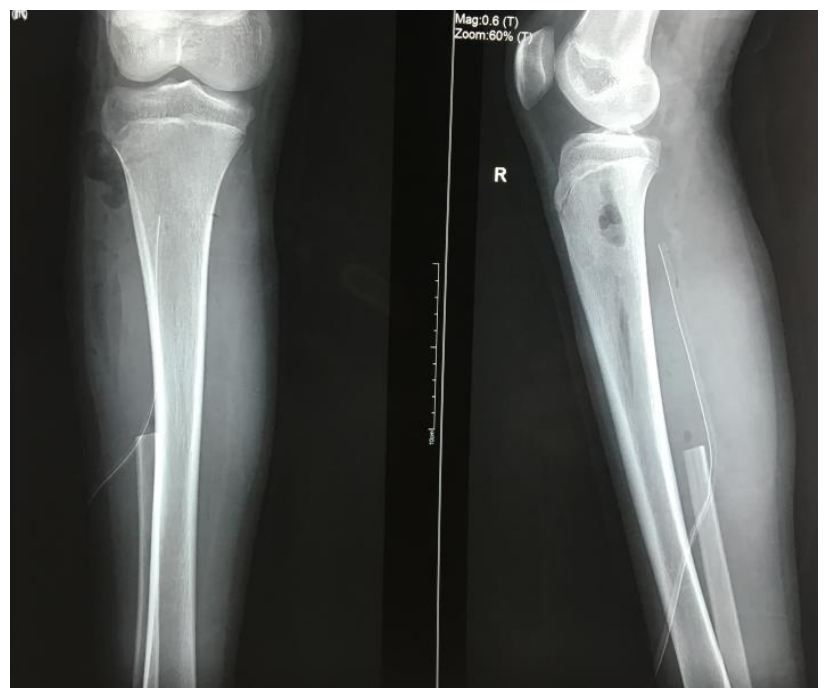

Figure 4: Post operative (Anteroposterior and Lateral) radiographs showing en-bloc excision of $\mathrm{ABC}$ from proximal end of fibula.

More than $90 \%$ cases of ABS are reported earlier the age of thirty, although it is a rare occurrence at the age of 13 as reported here. ${ }^{6}$ Aneurysmal bone cyst commonly located at the metaphysis region of long bones mostly proximal humerus, distal femur or in vertebral bodies and is eccentrically and expansile. Differential diagnosis of aneurysmal bone cyst comprise Giant cell tumor, osteoblastoma, chondroblastoma, chondromyxoid fibroma nonossifying fibroma and fibrous dysplasia. Aneurysmal bone cyst is distinguished with Unicameral 
bone cyst by MRI where the presence of a intralesional septations and double-density fluid level usually suggests an aneurysmal bone cyst. Given that the incidence of Aneurysmal bone cyst in proximal fibula is very low, treatment options are also few. ${ }^{7}$ Routine treatment procedure for Aneurysmal bone cyst is curretage and bone grafting, but since here the lesion involves the proximal end of fibula completely en-bloc excision is preferred. The precise etiology of aneurysmal bone cyst remains unknown. Biesecker et al states that because ABC's are frequently accompanied by associated lesions and because these associated lesions are rarely accompanied by $\mathrm{ABC}$ 's, it is probable that $\mathrm{ABC}$ 's are secondary to the associated lesions of bone therefore, the inaugural event of the genesis of ABC's most likely is an antecedent, primary lesion of bone. ${ }^{8}$ The next step in the pathophysiologic development of an $\mathrm{ABC}$ is probably the production of an abnormal vascular component by the precursor lesion of bone an arteriovenous fistula. While the tumor can be hostile in growth, it is benign and can be successfully treated with surgical excision. Few also have explained en bloc excision with allograft reconstruction for bony stability. ${ }^{9}$

\section{CONCLUSION}

Based on the literature till now, aneurysmal bone cyst developing at the level of proximal fibula is rare. Here we report a rare case of aneurysmal bone cyst at proximal end of fibula which was effectively managed with enbloc excision.

Funding: No funding sources Conflict of interest: None declared

Ethical approval: Not required

\section{REFERENCES}

1. Vergel De Dios AM, Bond JR, Shives TC, McLeod RA, Unni KK. Aneurysmal bone cyst. A clinicopathologic study of 238 cases. Cancer. 1992;69:2921-31.

2. Leithner A, Machacek F, Haas OA, Lang S, Ritschl P, Radl R, et al. Aneurysmal bone cyst: a hereditary disease? J Pediatr Orthop B. 2004;13:214-7.

3. Szendröi M, Cser I, Kónya A, Rényi-Vámos A. Aneurysmal bone cyst. A review of 52 primary and 16 secondary cases. Arch Orthop Trauma Surg. 1992;111(6):318-22.

4. Abuhassan FO, Shannak AO. Subperiosteal resection of aneurysmal bone cysts of the distal fibula. JBJS. 2009;91B:1227-31.

5. Jaffe HL, lichtenstein L. Solitary unicameral bone cyst with emphasis on the roentgen picture, the pathologic appearance and the pathogenesis. Arch Surg. 1942;44(6);1004-25.

6. Leithner A, Windhager R, Lang S, Haas OA, Kainberger F, Kotz R. Aneurysmal bone cyst. A population based epidemiologic study and literature review. Clin Orthop Relat Res. 1999;363:176-9.

7. Perisano C, Marzetti E, Spinelli MS, Graci C, Fabbriciani C, Maffulli $\mathrm{N}$ et al. Clinical management and surgical treatment of distal fibular tumours: a case series and review of the literature. Int Orthop. 2012;36(9):1907-13.

Cite this article as: Wadhawan P, Agrawal A, Khera R. Aneurysmal bone cyst of proximal fibula treated with en-bloc excision: a rare case report. Int J Res Orthop 2019;5:736-8. 